\title{
Functional and Proteomic Analyses Reveal That ScpBXv Is Involved in Bacte- rial Growth, Virulence, and Biofilm Formation in Xanthomonas campestris pv. vesicatoria
}

\author{
Hye-Jee Park and Sang-Wook Han* \\ Department of Integrative Plant Science, Chung-Ang University, Anseong 17546, Korea
}

(Received on July 13, 2017; Revised on July 26, 2017; Accepted on July 26, 2017)

Segregation and condensation protein B (ScpB) is essential for replication and segregation in living organisms. Here, we reported the functions of $\mathrm{ScpBXv}(\mathrm{ScpB}-$ like protein in Xanthomonas campestris pv. vesicatoria) using phenotypic and proteomic analyses. Growth of $\mathrm{Xcv} \Delta s c p B X v$ (ScpBXv knockout mutant) was reduced under both slow and fast growth conditions in rich medium, but comparable to this of the wild-type in plant-mimic conditions. Interestingly, the mutant was significantly less virulent than the wild-type in tomato, indicating that $\mathrm{ScpBXv}$ is involved in virulence. To investigate ScpBXv-associated mechanisms, comparative proteomic analyses were carried out and the abundance of 187 proteins was altered. Among them, diverse transcriptional regulators involved in biofilm formation and virulence were abundant in the wild-type. We further showed that biofilm formation of $\mathrm{Xcv} \Delta \operatorname{scp} B X v$ was reduced. This study provides new insights into the functions of ScpBXv in bacterial replication and biofilm formation, which may contribute to the virulence of $\mathrm{Xcv}$.

Keywords : proteomics, ScpB, Xanthomonas

Handling Associate Editor : Sohn, Kee Hoon

Xanthomonas species is Gram-negative, plant pathogenic bacterium that produce yellow pigments, and cause severe

\footnotetext{
*Corresponding author.

Phone) +82-31-670-3150, FAX) +82-2-670-8845

E-mail)swhan@cau.ac.kr

(c) This is an Open Access article distributed under the terms of the Creative Commons Attribution Non-Commercial License (http:// creativecommons.org/licenses/by-nc/4.0) which permits unrestricted noncommercial use, distribution, and reproduction in any medium, provided the original work is properly cited.
}

Articles can be freely viewed online at www.ppjonline.org. plant diseases in approximately 400 different plant species (Ryan et al., 2011). Among them, $X$. campestris pv. vesicatoria $(\mathrm{Xcv})$ causes a bacterial leaf spot disease on pepper and tomato, which is one of the most destructive diseases for these hosts (Vauterin et al., 1995). The bacterium is able to penetrate into their host through stomata, hydathodes, and wounded sites in humid conditions, and colonizes the intercellular area, forming water-soaked lesions. Subsequently, the disease causes small brown spots to appear on the leaf, stem, and fruit. The interaction between Xcv and its host have been studied extensively as a model system at the molecular level, and the Xcv genome sequence had been determined (Park et al., 2014a; Seong et al., 2016; Thieme et al., 2005; Wengelnik and Bonas, 1996).

Segregation and condensation protein $\mathrm{B}(\mathrm{ScpB})$ protein is one of components forming the structural maintenance of chromosomes (SMC) condensin complex, which plays pivotal roles in chromosome condensation and segregation in both eukaryotic and prokaryotic organisms (Hirano, 2006). In bacteria, ScpB from Bacillus subtilis is one of well-characterized ScpB proteins (Soppa et al., 2002; Wang et al., 2014). The $s c p B$ null mutant was not viable in the fast growth conditions and produced anucleate cells and formed aberrant nucleoids in the slow growth condition. In addition, Dervyn et al. (2004) reported that The SMCScpA-ScpB complex could interact physically with sensor histidine kinases and transcriptional regulators via ScpA to regulate gene expression in B. subtilis. This suggested that the SMC complex, containing the ScpA and ScpB proteins, might be involved in controlling gene expression. However, the functions of ScpB in Gram-negative bacteria, including Xanthomonas spp., are poorly understood.

To hypothesize and characterize the functions of genes/ proteins, diverse techniques, including transcriptomic and proteomic analyses, have been used. However, the expression patterns of proteins do not always correlate with 
those of RNAs because of post-transcriptional/translational modification, processing, and regulation (Gry et al., 2009). For example, a proteomic analysis revealed that the abundance of NanA, a putative $\mathrm{N}$-acetylneuraminate lyase, in Escherichia coli was reduced significantly (over 5 fold) after methyl-methane sulfonate treatment (Di Pasquale et al., 2016). However, the mRNA expression of the nanA gene was not altered. Therefore, protein profiles should be investigated to predict of gene/protein functions under specific conditions. In addition, the proteomic analysis of the ScpB family has not been reported.

In this study, we report the functions of ScpBXv (ScpBlike protein in Xcv. Accession No. MF040724) encoded by $X C V 2516$ in Xcv. To characterize ScpBXv functions, we generated a $s c p B X v$ knockout mutant $(\mathrm{Xcv} \Delta s c p B X v)$ and compared proteins levels and patterns between the wildtype and $\mathrm{Xcv} \triangle s c p B X v$ strains using label-free shotgun proteomic and cluster of orthologous group (COG) analyses. We also used several phenotypic assays, including the growth rate under various conditions, biofilm formation, and virulence. The results presented in this report allowed to elucidate the functions of ScpB-like proteins via a combination of phenotypic and proteomic characterization in Gram-negative bacterium.

$X$. campestris pv. vesicatoria $(\mathrm{Xcv})$ strain 85-10 (Thieme et al., 2005) was used as the wild-type in this study. Standard molecular techniques detailed in Sambrook et al. (1989) were used. To generate the knockout (KO) mutant (Xcv $\Delta s c p B X v$ ), the $1.2 \mathrm{kbp}$ region of $s c p B X v$ was amplified using gene specific primers (F: 5'-ttcactgccgaagaaggcaa-3, $\mathrm{R}$ : 5-taaacgaccagcaccgcaa-3'). The amplified fragment was ligated into the pGem T-easy vector (Madison, USA) and then digested by BamHI. The digested, cloned scpBXv gene was interrupted by the kanamycin-resistance cassette and the construct was introduced in Xcv by electroporation (Hercules, California, USA). To construct the plasmid for complementation, the open reading frame of $s c p B X v$ was amplified from Xcv genomic DNA by PCR using gene specific primers (F: 5'-ctcgagatgcgecgttgcaattctcc-3', R: 5'-gccggagccagacaccaccaccaccaccactgaagctt-3'). The amplified product was cloned into vector pGem T-easy and confirmed by sequence analysis. The construct was digested with XhoI and HindIII and ligated into the broad host range vector pBBR1-MCS5 (Kovach et al., 1995). The plasmid was introduced into $\mathrm{Xcv} \triangle s c p B X v$ and the complemented strain, $\mathrm{Xcv} \Delta s c p B X v$ (ScpBXv) was confirmed by PCR. The empty pBBR1-MCS5 vector was also introduced into $\mathrm{Xcv}$ and $\mathrm{Xcv} \Delta s c p B X v$, generating both $\mathrm{Xcv}$ (MCS5) and $\mathrm{Xcv} \Delta s c p B X v$ (MCS5), which were used as the wild-type and $s c p B X v$ mutant in this study.
A

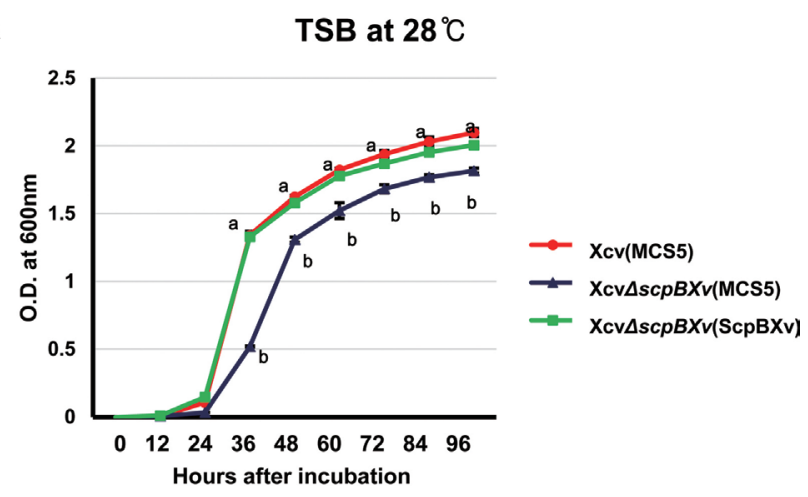

B

TSB at $22^{\circ} \mathrm{C}$

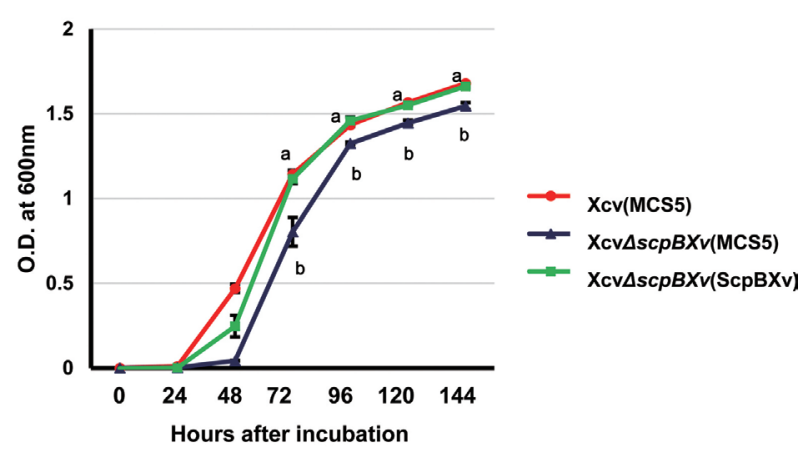

C

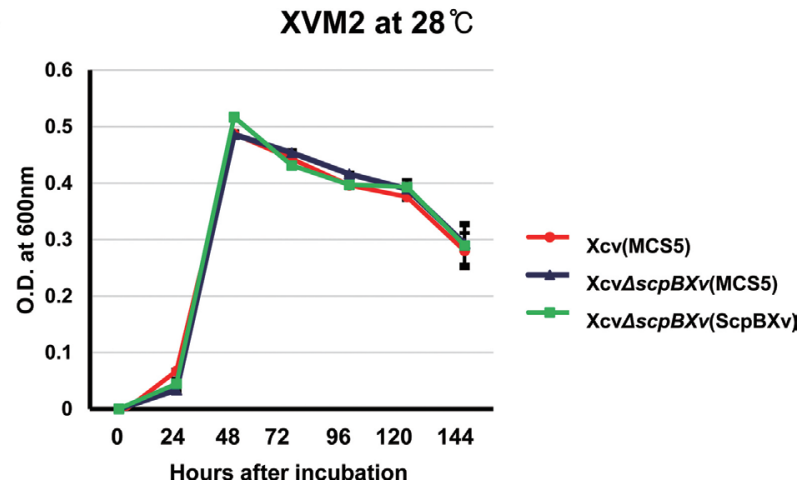

Fig. 1. ScpBXv is essential for bacterial growth. Bacterial strains were resuspended in media at $10^{5}$ cells $/ \mathrm{mL}$ for Xcv (MCS5) (red), $\mathrm{Xcv} \Delta s c p B X v$ (MCS5) (blue), and $\mathrm{Xcv} \Delta s c p B X v$ (ScpBXv) (green); bacterial growth was measured using a spectrophotometer at $600 \mathrm{~nm}$. The $\mathrm{Xcv}$ strains were incubated (A) at $28^{\circ} \mathrm{C}$ in tryptic soy broth (TSB), (B) at $22^{\circ} \mathrm{C}$ in TSB, and (C) at $28^{\circ} \mathrm{C}$ in $\mathrm{XVM}$ 2. Error bars represent the standard error of the mean. Different letters on the bars represent significant differences (using the least significant difference test, $P \leq 0.05$ ). All experiments were repeated at least four times with three biological replicates.

$\mathrm{ScpB}$ is known to be involved in bacterial reproduction (Soppa et al., 2002; Wang et al., 2014). For example, the $s c p B \mathrm{KO}$ mutant in $B$. subtilis was lethal at $37^{\circ} \mathrm{C}$ (fast growth condition), whereas the mutant was viable, but its growth was reduced at $23^{\circ} \mathrm{C}$ (slow growth condition) 
compared to the wild-type. Therefore, we investigated the effects of ScpBXv on Xcv growth in fast $\left(28^{\circ} \mathrm{C}\right)$ and slow $\left(22^{\circ} \mathrm{C}\right)$ growth conditions (Fig. 1). In contrast to $\mathrm{ScpB}$ in B. subtilis, $\mathrm{Xcv} \triangle s c p B X v$ (MCS5) was viable in both fast and slow growth conditions (Fig. 1A, 1B). In addition, the growth of $\mathrm{Xcv} \Delta s c p B X v$ (MCS5) was slower than this of $\mathrm{Xcv}$ (MCS5) in both conditions. In the wild-type strain, the exponential phase started at $12 \mathrm{~h}$ and $24 \mathrm{~h}$ after incubation in the fast and slow conditions, respectively. However, the growth of the mutant was retarded (about two-fold) from entering the exponential phase in both conditions compared with the wild-type, indicating that the $s c p B X v$ gene is also involved in adaptation or preparation for the exponential phase in Xcv. The growth of the complemented strain, $\mathrm{Xcv} \Delta s c p B X v(\mathrm{ScpBXv})$, was comparable to that of the wild-type in both media (Fig. 1A, B), indicating that the mutant used in this study did not have a polar effect. These results indicated that the function of $\mathrm{ScpBXv}$ in $\mathrm{Xcv}$ is slightly different from that in $B$. subtilis because the scpB knockout mutant of $B$. subtilis was lethal under the fast growth condition. It is also possible that $\mathrm{Xcv}$ possesses other proteins that can compensate for the functions of $\mathrm{ScpBXv}$ in the given conditions. We also tested the growth of the mutant in XVM2, which is a defined, plant-mimic growth condition medium. XVM2 has been used to study virulence-related gene expression and function because the medium is similar to in planta conditions (Wengelnik et al., 1996a, b). Strikingly, the three strains, Xcv (MCS5), $\mathrm{Xcv} \triangle s c p B X v$ (MCS5), and $\mathrm{Xcv} \Delta s c p B X v$ (ScpBXv), displayed similar growth patterns in XVM2 (Fig. 1C), indicating that ScpBXv did not have any effect on the growth of $\mathrm{Xcv}$ under synthetic, plant-mimic conditions.

Dervyn et al. reported that the SMC-ScpA-ScpB complex regulated gene expression via a two component system (TCS), DegS and DegU, which is involved in virulence (Dervyn et al., 2004; Murray et al., 2009). Therefore, we examined the virulence of $\mathrm{Xcv} \Delta s c p B X v$ (MCS5) toward tomato plants by checking bacterial growth on the plants. Xcv strains $\left(10^{5}\right.$ colony forming units $\left./ \mathrm{mL}\right)$ were inoculated into VF36 tomato plants (Kim et al., 2013) by infiltration with a needle-less syringe. Both the wild-type and the complemented strains showed clear disease symptoms on all leaves at 15 days after inoculation (Fig. 2A). However, the leaves infected by $\mathrm{Xcv} \Delta s c p B X v$ (MCS5) still displayed a greenish color. In addition, the bacterial growth patterns of three strains were compared for 9 days in 3-day intervals (Fig. 2B). The number of Xcv $\Delta s c p B X v$ (MCS5) in the infected tomato leaves was dramatically reduced (over 10-fold) compared with that of Xcv (MCS5), demonstrating that the mutant has reduced virulence compared with
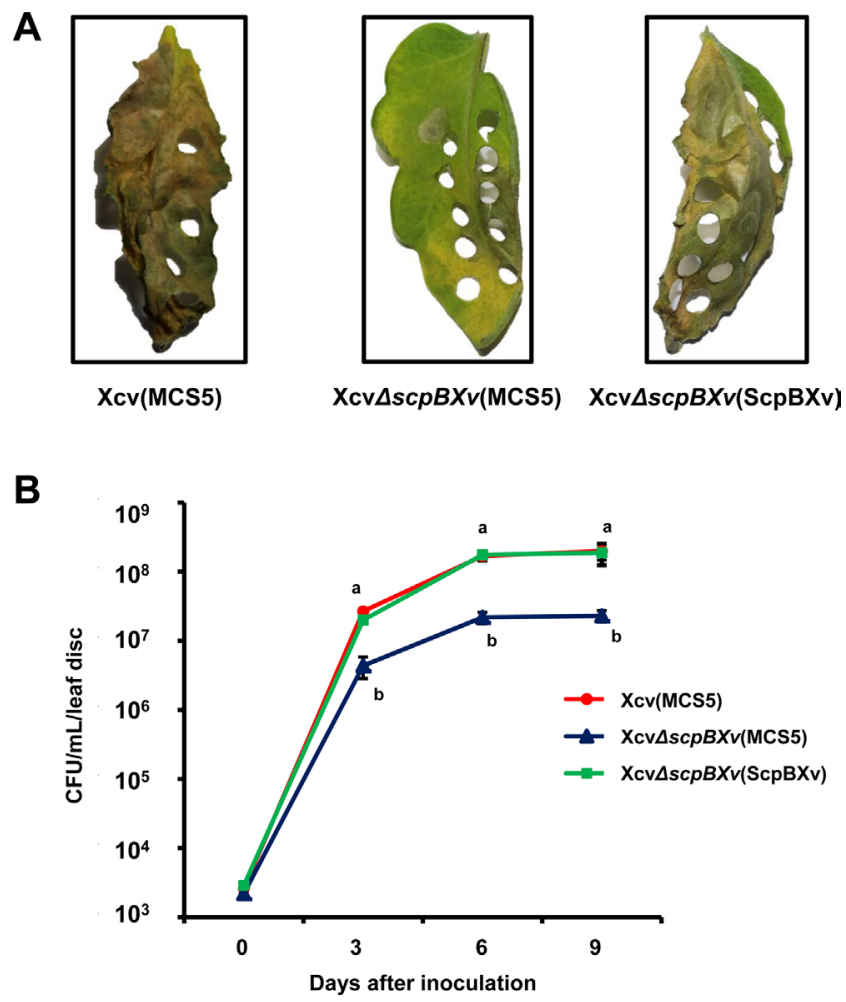

Fig. 2. The ScpBXv is involved in virulence of Xcv toward tomato plants. Suspensions of $10^{5}$ cells $/ \mathrm{mL}$ of Xcv (MCS5), $\mathrm{Xcv} \Delta s c p B X v(\mathrm{MCS} 5)$, and $\mathrm{Xcv} \Delta s c p B X v(\mathrm{scpBXv})$ strains were infiltrated onto 3-week-old tomato leaves using a needless syringe. (A) A photograph taken 12 days after incubation. (B) Bacterial growth of $\mathrm{Xcv}$ (MCS5) (red), $\mathrm{Xcv} \Delta s c p B X v$ (MCS5) (blue), and $\mathrm{Xcv} \Delta s c p B X v(\mathrm{ScpBXv})$ (green) strains were measured by the plate counting method after serial dilution at 3-day intervals. Bars represent the mean of three biological replicates with the standard deviations. Different letters on the bars represent significant differences (using the least significant difference test, $P \leq 0.05$ ). All experiments were repeated at least four times with three biological replicates.

that of the wild-type. Growth of the complemented strain was restored to the wild-type level. The growth patterns of the wild-type and the mutant were similar in plant-mimic conditions (Fig 1C); therefore, these results suggested that ScpBXv is indispensable for full virulence and/or optimal growth in tomato plants.

It is clear that ScpBXv is involved in replication in fast and slow growth conditions, as well as in the virulence of Xcv. In addition, the SMC-ScpA-ScpB complex is involved in regulation of gene expression in B. subtilis (Dervyn et al., 2004; Wang et al., 2014). Therefore, to predict ScpBXv functions and to identify its related cellular and biological process, patterns of protein abundance in the wild-type and $\mathrm{X} \operatorname{cv} \triangle \operatorname{sc} B X X v$ were compared using a label- 
free shotgun proteomic technique as described previously. (Park et al., 2014a, 2016). Briefly, Xcv strains grown in tryptic soy broth were harvested at an optical density at $600 \mathrm{~nm}\left(\mathrm{OD}_{600}\right)$ of 0.3 . Proteins from three biological replicates were extracted and digested with trypsin (Promega). After washing with the Sep-Pak Vac 1-cc tC18 cartridges (Waters), tryptic-digested peptides were loaded onto an LTQ Velos Pro instrument (Waltham, Massachusetts, USA) combined with a split free nano-liquid chromatography column (LC, EASY-nLC II, ThermoFisher). Raw data were imported into ThermoFisher (Waltham, Massachusetts, USA) via SEQUEST to identify the presence of proteins/peptides by comparison against the Xcv strain 85-10 databases from the National Center for Biotechnology Information. All accepted Xcv peptides showed 0.01 a false discovery rate and the probability scores were at least 20. Proteins showing at least two unique peptides were selected. Selected proteins were imported again into Scaffold 4 (Portland, Oregon, USA) for comparison. Peptide spectrum match (PSM) scores were used as the comparative values (Choi et al., 2008). PSMs from an individual protein were normalized against the total PSMs from a sample and the proteins detected in the three biological replicates were used. The mean PSM values of the three replicates were calculated per protein to show differentially (over 2-fold) abundant proteins. Finally $t$-test was carried out for statistical analysis.

At least 70,000 PSMs were found in all three biologi- cal replicates from the wild-type and $\mathrm{Xcv} \triangle \operatorname{scp} B X v$ strains (Supplementary Table 1). From PSMs, 1322, 1335, and 1375 proteins were assigned as present in the wild-type; and 1342,1381 , and 1265 were in $\mathrm{Xcv} \Delta s c p B X v$. Among these proteins, a total of 1189 and 1141 proteins were shared commonly in the three biological replicates from the wild-type and $\mathrm{Xcv} \Delta s c p B X v$, respectively (Supplementary Table 1), and these shared proteins were used for comparative analysis. We found that 102 and 85 proteins were differentially (by over 2-fold) abundant in the wild-type and $\mathrm{Xcv} \triangle s c p B X v$, respectively (Supplementary Table S2, S3). Taking into account the 4726 predicted coding sequences in the genome (Thieme et al., 2005), these data indicated that the levels of about $4.0 \%$ of proteins in Xcv were affected directly or indirectly by ScpBXv.

Next, to predict ScpBXv's functions and its related cellular mechanisms, clusters of orthologous groups (COG) analysis (Tatusov et al., 2000), which has been used widely to classify proteins and predict their function, was employed for the 187 proteins whose levels was altered. Proteins belonging to cell wall/membrane/envelop biogenesis, intracellular trafficking, and defense mechanisms were more abundant in the mutant compared with the wild-type (Fig. 3). However, proteins related to transcription, coenzyme metabolism, and signal transduction were highly expressed in the wild-type compared with Xcv $\triangle s c p B X v$ (Fig. $3)$. Among these proteins, six of transcriptional regulators, including LacI, IcIR, and LysR types, and four of TCS-

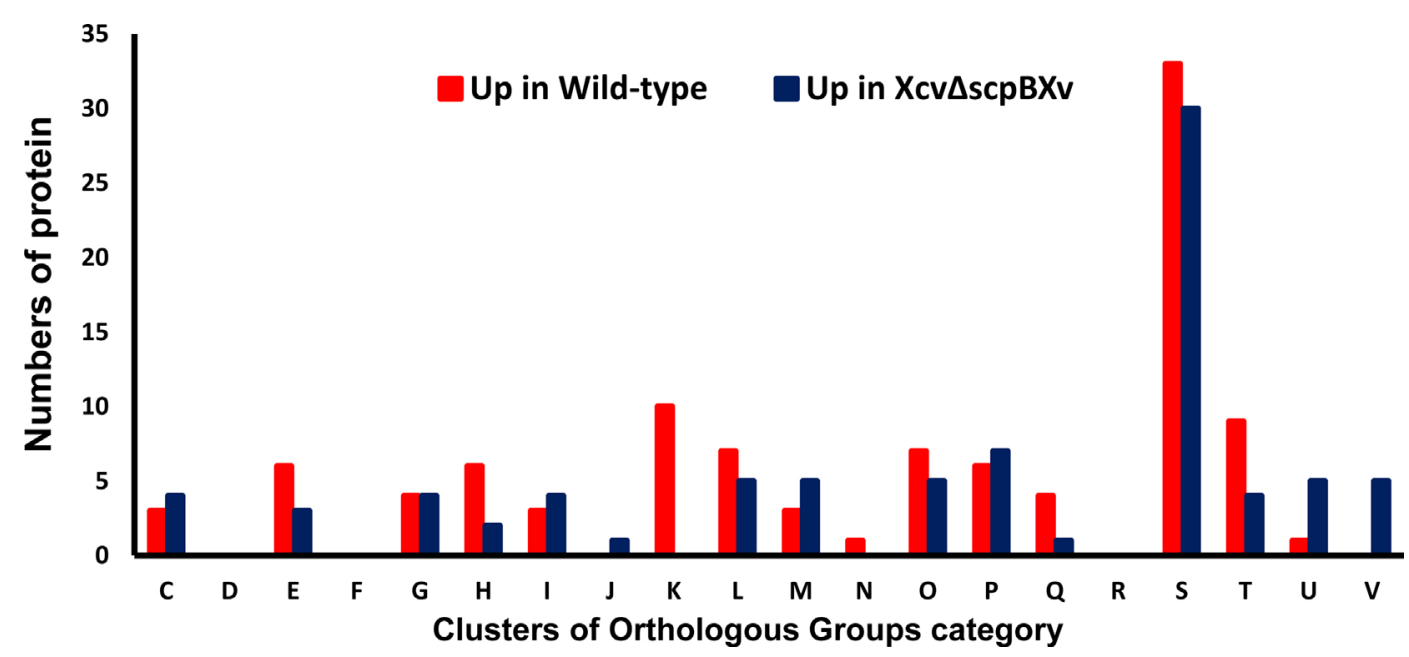

Fig. 3. Clusters of Orthologous Groups analysis of 187 proteins regulated by ScpBXv. Red and blur bars indicate that differentially abundant (over 2-fold) in the wild-type and Xcv $\Delta s c p B X v$, respectively. C, Energy production and conversion; D, Cell cycle control and mitosis; E, amino acid metabolism and transport; F, nucleotide metabolism and transport; G, carbohydrate metabolism and transport; H, coenzyme metabolism; I, lipid metabolism; J, translation; K, transcription; L, replication and repair; M, cell wall/membrane/envelop biogenesis; N, cell motility; $\mathrm{O}$, post-translational modification, protein turnover, chaperone functions; $\mathrm{P}$, inorganic ion transport and metabolism; Q, secondary structure; R, general functional prediction only; S, function unknown; T, signal transduction; U, intracellular trafficking and secretion; and $\mathrm{V}$, defense mechanisms. 
related proteins were found in transcription or signal transduction categories in the wild-type (Supplementary Table 2). However, any transcriptional regulators were not listed in the mutant (Supplementary Table 3). As mentioned previously, the SMC-ScpA-ScpB complex is associated with controlling gene expression through the TCS systems and IcIR-type transcriptional regulators (Dervyn et al., 2004). Similarly, the comparative proteomic analysis suggested that TCS systems and transcriptional regulators are associated with ScpBXv-mediated mechanisms in Xcv. These data suggest that $\mathrm{ScpBXv}$ is involved in bacterial reproduction/replication as well as regulation of protein expression in Xcv.

The LacI, IcIR, and LysR-type transcriptional regulators are involved in the regulation of virulence and biofilm formation in bacteria (Aguilar et al., 2014; Mao et al., 2017; Sadykov et al., 2011). In addition, biofilm formation correlates with virulence in pathogenic bacteria (Ham, 2013; Torres et al., 2007). Therefore, biofilm formation was examined using a 96-well PVC plate assay as described previously (Park et al., 2014b) because Xcv $\Delta s c p B X v$ was less virulent than the wild-type and five of LacI, IcIR, and LysR-type regulators were only detected in the wild-type. To prevent an effect from their different growth abilities, XVM2 medium was used for this assay because the growth of $\mathrm{Xcv} \triangle s c p B X v$ did not differ from that of $\mathrm{Xcv}(\mathrm{MCS} 5)$ in

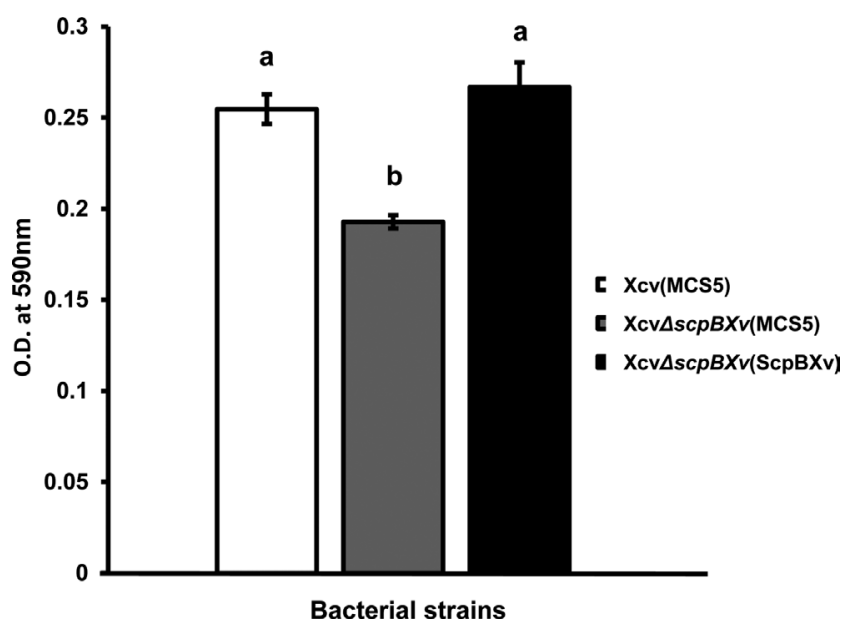

Fig. 4. Xcv $\Delta s c p B X v$ displayed reduced biofilm formation. Biofilm formation of strains Xcv (MCS5) (white bar), Xcv $\Delta s c p B X v$ (MCS5) (gray bar), and $\mathrm{Xcv} \Delta s c p B X v$ (ScpBXv) (black bar) was quantified by measuring the absorbance at A590 nm using the crystal violet staining assay in 96-well plates. Error bars represent the standard error of the mean. Different letters on the bars represent significant differences (using the least significant difference test, $P \leq 0.05$ ). All experiments were repeated at least four times with sixteen biological replicates. this medium. The biofilm formation ability of $\mathrm{Xcv} \Delta s c p B X v$ was significantly reduced compared with that of the wildtype, suggesting that ScpBXv is involved in the regulation of biofilm formation (Fig. 4). The complemented strain restored the ability to form a biofilm to the level of the wildtype. Plants often produce and secrete antimicrobial agents against bacterial infection and the bacterial biofilm is a well-characterized strategy to protect themselves against these agents or harsh environments. Thus, reduction of biofilm formation might be one of major factors that caused the attenuated virulence of $\mathrm{Xcv} \Delta s c p B X v$.

In this report, we employed diverse functional assays and comparative proteomic analysis to characterize the roles of the protein encoded by $s c p B X v$, a previously unreported gene in Xcv. Although it is clear that $\mathrm{ScpBXv}$ is involved in bacterial replication, similar to other $\mathrm{ScpB}$ proteins, the protein might have different roles in $\mathrm{Xcv}$, because the growth patterns of $\mathrm{Xcv} \Delta s c p B X v$ were not identical to the previously reported $\mathrm{ScpB}$ mutant under the given conditions. In addition, we further demonstrated that ScpBXv is involved in bacterial virulence and biofilm formation, indicating that it might possess other functions in $\mathrm{Xcv}$, which are currently under-investigation. Finally, our findings also suggested that comparative proteomic analysis was very effective to suggest the roles of a protein of interest.

\section{Acknowledgments}

This work was supported by the Basic Science Research Program through the National Research Foundation of Korea (NRF) funded by the Ministry of Science, ICT \& Future Planning [NRF-2015R1A2A2A01004242]; the NextGeneration BioGreen 21 Program [PJ01103301] of the Rural Development Administration, Republic of Korea (to SW Han). This research was supported by the Chung-Ang University Graduate Research Scholarship in 2015 (to HJ Park).

\section{References}

Aguilar, C., Schmid, N., Lardi, M., Pessi, G. and Eberl, L. 2014. The IclR-family regulator BapR controls biofilm formation in B. cenocepacia H111. PLos One 9:e92920.

Choi, H., Fermin, D. and Nesvizhskii, A. I. 2008. Significance analysis of spectral count data in label-free shotgun proteomics. Mol. Cell Proteomics 7:2373-2385.

Dervyn, E., Noirot-Gros, M. F., Mervelet, P., McGovern, S., Ehrlich, S. D., Polard, P. and Noirot, P. 2004. The bacterial condensin/cohesin-like protein complex acts in DNA repair and regulation of gene expression. Mol. Microbiol. 51:1629-1640.

Di Pasquale, P., Caterino, M., Di Somma, A., Squillace, M., 
Rossi, E., Landini, P., Palamara, A. T. and Duilio, A. 2016. Exposure of E. coli to DNA-methylating agents impairs Biofilm formation and invasion of eukaryotic cells via down regulation of the $\mathrm{N}$-acetylneuraminate lyase nanA. Front. Microbiol. 7:147.

Gry, M., Rimini, R., Stromberg, S., Asplund, A., Ponten, F., Uhlen, M. and Nilsson, P. 2009. Correlations between RNA and protein expression profiles in 23 human cell lines. BMC Genomics 10:365.

Ham, J. H. 2013. Intercellular and intracellular signalling systems that globally control the expression of virulence genes in plant pathogenic bacteria. Mol. Plant Pathol. 14:308-322.

Hirano, T. 2006. At the heart of the chromosome: SMC proteins in action. Nat. Rev. Mol. Cell Biol. 7:311-322.

Kim, J. G., Stork, W. and Mudgett, M. B. 2013. Xanthomonas type III effector xopd desumoylates tomato transcription factor SIERF4 to suppress ethylene responses and promote pathogen growth. Cell Host Microbe 13:143-154.

Kovach, M. E., Elzer, P. H., Hill, D. S., Robertson, G. T., Farris, M. A., Roop, R. M., 2nd and Peterson, K. M. 1995. Four new derivatives of the broad-host-range cloning vector $\mathrm{pB}$ BR1MCS, carrying different antibiotic-resistance cassettes. Gene 166:175-176.

Mao, D. N., Bushin, L. B., Moon, K., Wu, Y. H. and Seyedsayamdost, M. R. 2017. Discovery of $s c m R$ as a global regulator of secondary metabolism and virulence in Burkholderia thailandensis E264. Proc. Natl. Acad. Sci. U.S.A. 114:E2920E2928.

Murray, E. J., Kiley, T. B. and Stanley-Wall, N. R. 2009. A pivotal role for the response regulator DegU in controlling multicellular behaviour. Microbiology 155:1-8.

Park, H. J., Jung, H. W. and Han, S. W. 2014a. Functional and proteomic analyses reveal that $w x c B$ is involved in virulence, motility, detergent tolerance, and biofilm formation in Xanthomonas campestris pv. vesicatoria. Biochem. Biophys. Res. Commun. 452:389-394.

Park, H. J., Lee, S. W. and Han, S. W. 2014b. Proteomic and functional analyses of a novel porin-like protein in Xanthomonas oryzae pv. oryzae. J. Microbiol. 52:1030-1035.

Park, H. J., Park, C. J., Bae, N. and Han, S. W. 2016. Deciphering the role of tyrosine sulfation in Xanthomonas oryzae pv. oryzae using shotgun proteomic analysis. Plant Pathol. J. 32:266-272.

Ryan, R. P., Vorholter, F. J., Potnis, N., Jones, J. B., Van Sluys, M. A., Bogdanove, A. J. and Dow, J. M. 2011. Pathogenomics of Xanthomonas: understanding bacterium-plant interactions. Nat. Rev. Microbiol. 9:344-355.

Sadykov, M. R., Hartmann, T., Mattes, T. A., Hiatt, M., Jann, N. J., Zhu, Y., Ledala, N., Landmann, R., Herrmann, M., Rohde, H., Bischoff, M. and Somerville, G. A. 2011. CcpA coordinates central metabolism and biofilm formation in staphylococcus epidermidis. Microbiology 157:3458-3468.

Sambrook, J., Fritsch, E. F. and Maniatis, T. 1989. Molecular cloning: a laboratory manual. Cold Spring Harbor Laboratory Press, New York.

Seong, H. J., Park, H. J., Hong, E., Lee, S. C., Sul, W. J. and Han, S. W. 2016. Methylome analysis of two Xanthomonas spp. using single-molecule real-time sequencing. Plant Pathol. J. 32:500-507.

Soppa, J., Kobayashi, K., Noirot-Gros, M. F., Oesterhelt, D., Ehrlich, S. D., Dervyn, E., Ogasawara, N. and Moriya, S. 2002. Discovery of two novel families of proteins that are proposed to interact with prokaryotic SMC proteins, and characterization of the Bacillus subtilis family members ScpA and ScpB. Mol. Microbiol. 45:59-71.

Tatusov, R. L., Galperin, M. Y., Natale, D. A. and Koonin, E. V. 2000. The COG database: a tool for genome-scale analysis of protein functions and evolution. Nucleic Acids Res. 28:33-36.

Thieme, F., Koebnik, R., Bekel, T., Berger, C., Boch, J., Büttner, D., Caldana, C., Gaigalat, L., Goesmann, A., Kay, S., Kirchner, O., Lanz, C., Linke, B., McHardy, A. C., Meyer, F., Mittenhuber, G., Nies, D. H., Niesbach-Klösgen, U., Patschkowski, T., Rückert, C., Rupp, O., Schneiker, S., Schuster, S. C., Vorhölter, F. J., Weber, E., Pühler, A., Bonas, U., Bartels, D. and Kaiser, O. 2005. Insights into genome plasticity and pathogenicity of the plant pathogenic bacterium Xanthomonas campestris pv. vesicatoria revealed by the complete genome sequence. J. Bacteriol. 187:7254-7266.

Torres, P. S., Malamud, F., Rigano, L. A., Russo, D. M., Marano, M. R., Castagnaro, A. P., Zorreguieta, A., Bouarab, K., Dow, J. M. and Vojnov, A. A. 2007. Controlled synthesis of the DSF cell-cell signal is required for biofilm formation and virulence in Xanthomonas campestris. Environ. Microbiol. 9:21012109.

Vauterin, L., Hoste, B., Kersters, K. and Swings, J. 1995. Reclassification of Xanthomonas. Int. J. Syst. Bacteriol. 45:472-489.

Wang, X. D., Tang, O. W., Riley, E. P. and Rudner, D. Z. 2014. The SMC condensin complex is required for origin segregation in Bacillus subtilis. Curr. Biol. 24:287-292.

Wengelnik, K. and Bonas, U. 1996. HrpXv, an AraC-type regulator, activates expression of five of the six loci in the hrp cluster of Xanthomonas campestris pv. vesicatoria. J. Bacteriol. 178:3462-3469.

Wengelnik, K., Marie, C., Russel, M. and Bonas, U. 1996a. Expression and localization of HrpA1, a protein of Xanthomonas campestris pv. vesicatoria essential for pathogenicity and induction ofthe hypersensitive reaction. J. Bacteriol. 178:1061-1069.

Wengelnik, K., Van den Ackerveken, G. and Bonas, U. 1996b. HrpG, a key hrp regulatory protein of Xanthomonas campestris pv. vesicatoria is homologous to two-component response regulators. Mol. Plant-Microbe Interact. 9:704-712. 